\title{
Antimicrobial resistance of bacteria isolated from patients with bloodstream infections at a tertiary care hospital in the Democratic Republic of the Congo
}

\author{
L M Irenge,${ }^{1,2,3} \mathrm{MD}$, PhD; L Kabego, ${ }^{1} \mathrm{MD} ; \mathbf{F}$ B Kinunu, ${ }^{1}$ MSc; M Itongwa, ${ }^{1} \mathrm{MSc} ; \mathbf{P}$ N Mitangala, ${ }^{4} \mathrm{MD}, \mathrm{PhD} ; \mathrm{J}-\mathrm{L}$ Gala, ${ }^{2,3} \mathrm{MD}, \mathrm{PhD}$ \\ R B Chirimwami, ${ }^{1} \mathrm{MD}, \mathrm{PhD}$ \\ ${ }^{1}$ Bukavu General Hospital/Université Catholique de Bukavu, Bukavu, Democratic Republic of the Congo \\ ${ }^{2}$ Centre for Applied Molecular Technologies, Institut de Recherche Expérimentale et Clinique, Université catholique de Louvain, Brussels, Belgium \\ ${ }^{3}$ Defence Laboratories Department, Belgian Armed Forces, Peutie, Belgium \\ ${ }^{4}$ Laboratoire Provincial de Santé Publique du Nord Kivu, Goma, Democratic Republic of the Congo
}

Corresponding author: L M Irenge (leonid.irenge@uclouvain.be)

\begin{abstract}
Background. Bloodstream infection (BSI) is a life-threatening condition that requires rapid antimicrobial treatment.
Methods. We determined the prevalence of bacterial isolates associated with BSI at Bukavu General Hospital (BGH), South Kivu Province, Democratic Republic of the Congo, and their patterns of susceptibility to antimicrobial drugs, from February 2013 to January 2014.

Results. We cultured 112 clinically relevant isolates from 320 blood cultures. Of these isolates, $104(92.9 \%)$ were Gram-negative bacteria (GNB), with 103 bacilli (92.0\%) and one coccus (0.9\%). Among GNB, Escherichia coli (51.9\%), Klebsiella spp. (20.2\%), Enterobacter spp. (6.7\%), Shigella spp. (5.8\%) and Salmonella spp. (4.8\%) were the most frequent agents causing BSIs. Other GNB isolates included Proteus spp., Citrobacter spp. and Pseudomonas aeruginosa (both 2.9\%), and Acinetobacter spp. and Neisseria spp. (both 0.9\%). High rates of resistance to co-trimoxazole (100\%), erythromycin $(100 \%)$ and ampicillin $(66.7-100 \%)$ and moderate to high resistance to ciprofloxacin, ceftazidime, ceftriaxone, cefuroxime and cefepime were observed among GNB. Furthermore, there were high rates of multidrug resistance and of extended-spectrum $\beta$-lactamase (ESBL) production phenotype among Enterobacteriaceae. Gram-positive bacteria included three Staphylococcus aureus isolates (2.7\%), four oxacillin-resistant coagulase-negative staphylococci (CoNS) isolates (3.6\%) and one Streptococcus pneumoniae (0.9\%). No oxacillin-resistant $S$. aureus was isolated. Among clinically relevant staphylococci, susceptibility to co-trimoxazole and ampicillin was low $(0-25 \%)$. In addition, 58 contaminant CoNS were isolated from blood cultures, and the calculated ratio of contaminants to pathogens in blood cultures was 1:2.

Conclusions. Multidrug-resistant and ESBL-producing GNB are the leading cause of BSI at BGH.
\end{abstract}

S Afr Med J 2015;105(9):752-755. DOI:10.7196/SAMJnew.7937

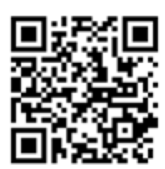

Bloodstream infection (BSI) refers to the presence of microbial pathogens in the blood. These are present as a result of infection, not specimen contamination. ${ }^{[1-3]} \mathrm{BSI}$ is a major cause of community and healthcare-associated infections and is associated with high mortality. ${ }^{[3-7]}$

Infectious diseases are the leading cause of death in the Democratic Republic of the Congo (DRC) ${ }^{[8]}$ In fact, the DRC has a crude mortality rate well above the average for sub-Saharan countries ${ }^{[9]}$ and the highest under-5 mortality rate in Africa, ${ }^{[10]}$ with malaria, pneumonia and diarrhoea the leading causes of death. ${ }^{[1,12]}$ In South Kivu Province, most healthcare facilities lack the capacity to identify causative agents of infectious diseases reliably, including invasive bacterial infections such as BSIs. BSI and malaria are practically indistinguishable on clinical examination, ${ }^{[13]}$ and available World Health Organization (WHO) guidelines for managing childhood illnesses fail to identify up to half of the cases of BSI. ${ }^{[14]}$ In view of the fact that fever - a symptom common to malaria and BSI - is the most frequent reason for presentation to hospital in most developing countries, ${ }^{[5,15]}$ the development of laboratory capacity for identification of pathogens is critical in order to improve the outcome of febrile diseases and enable rapid differential diagnosis between malaria and BSI. ${ }^{[16,17]}$ We report the results of our first year's experience using blood cultures in the laboratory of Bukavu General
Hospital (BGH), South Kivu Province, in order to identify pathogens involved in BSIs. This report follows on from a previous study that documented a high rate of antimicrobial drug-resistant isolates in patients with urinary tract infections at the same healthcare facility. ${ }^{[18]}$

\section{Methods}

Study design

This cross-sectional study was conducted in inpatients in various wards of BGH who were suspected of having BSI. This hospital has 385 beds, handles 6400 admissions and 4900 outpatients per year, and is one of the main healthcare facilities in Bukavu, a city of more than 500000 inhabitants in South Kivu Province in eastern DRC.

\section{Laboratory methods}

BAC/ALERT FA FAN Aerobic and BAC/ALERT FA FAN Anaerobic blood culture bottles and BAC/ALERT PF Pediatric FAN (Biomérieux, Belgium) were dispatched to various wards of the hospital. The decision to perform blood culture was based on the following criteria: fever (temperature $>38.0^{\circ} \mathrm{C}$ ), a negative thick blood smear for detection of Plasmodium spp., and a white blood cell count of $>10 \times 10^{9} / \mathrm{L}$ with $>70 \%$ neutrophils. Nurses were instructed to sample blood during a febrile episode. For sampling, the patient's skin was cleaned with $70 \%$ ethanol and allowed to dry prior to venous puncture. Blood was collected using strict aseptic technique, and approximately $10 \mathrm{~mL}$ 
for adult patients was immediately inoculated into the BAC/ALERT FA FAN Aerobic and BAC/ALERT FA FAN Anaerobic blood culture bottles. In the case of children, $2-5 \mathrm{~mL}$ of blood was inoculated in a BAC/ALERT PF Pediatric FAN. The inoculated vials were incubated straight away at $37^{\circ} \mathrm{C}$ for up to 7 days. The vials were checked visually every day to detect any colour change at the bottom of the bottle, from a blue-green to a yellow colour. For vials displaying a positive signal, cultures were Gram-stained and subcultures performed on 5\% sheep blood agar plates for staphylococci. For Streptococcus, a disc of optochin was added to the streaked blood agar plate and incubation was carried out at $37^{\circ} \mathrm{C}$ in a $5 \% \mathrm{CO}_{2}$ atmosphere. Subculture of Gramnegative bacilli was performed on MacConkey agar, whereas Gram-negative cocci were subcultured on chocolate agar. Standard biochemical methods were subsequently used to identify bacteria at the species level. ${ }^{[19]}$

Antimicrobial susceptibility tests were performed using the disc diffusion method on Mueller-Hinton agar II (BioRad, Nazareth Eke, Belgium), and the results were interpreted according to the guidelines of the European Committee on Antimicrobial Susceptibility Testing (EUCAST, 2015). ${ }^{[20]}$ Antibiotic discs were purchased from Bio-Rad (Nazareth Eke). For isolates of staphylococci, testing of antimicrobial drug susceptibility to ampicillin, amikacin, clindamycin, erythromycin, gentamicin, oxacillin and vancomycin was performed. In order to assess the antimicrobial drug susceptibility pattern of Gram-negative isolates, ampicillin, gentamicin, amoxicillinclavulanic acid, ceftriaxone, cefuroxime, ceftazidime, cefepime, imipenem, amikacin, ciprofloxacin, erythromycin and clindamycin were tested. Isolates showing resistance to at least one cephalosporin were tested for extended-spectrum $\beta$-lactamase (ESBL) production by the double-disc synergy test on Mueller-Hinton agar using ceftazidime and ceftriaxone placed at a distance of 20 $\mathrm{mm}$ from a disc containing amoxicillin plus clavulanic acid. A clear-cut enhancement of the inhibition in front of either ceftazidime and ceftriaxone discs towards the clavulanic acid-containing disc (also called 'champagne cork' or 'keyhole') was interpreted as positive for ESBL production. ${ }^{[21]}$ E-test strips (BioMérieux, France) were used for confirmation of ESBL production. Minimum inhibitory concentrations of cefotaxime and ceftazidime, with and without clavulanic acid, were determined after 16 - 18 hours' incubation on Mueller-Hinton plates inoculated with suspension of isolates at a fixed density (0.5 - 0.6 McFarland standard).
Escherichia coli ATCC 35218 and Klebsiella pneumoniae ATCC 700603 strains were used as ESBL-negative and positive controls, respectively. Multidrug resistance (MDR) was defined as non-susceptibility to at least one agent in three or more antimicrobial categories. $^{[16]}$ All MDR isolates were cryopreserved at $-80^{\circ} \mathrm{C}$ for further studies, with the exception of methicillin-resistant coagulase-negative staphylococci (CoNS), all CoNS being considered contaminants.

\section{Statistical analysis}

Statistical analyses were performed using the SPSS statistical package release 12.0 for Windows (SPSS, USA). Comparisons of proportions of bacteria isolated and antimicrobial susceptibility results were analysed using the $\chi^{2}$ test. The level of significance was $p<0.05$.

\section{Ethics}

Ethical approval was granted by the Ethical Committee of the Université catholique de Bukavu, DRC, and the DRC Ministry of Health. The study complies with WHO and international guidelines (European Society of Clinical Microbiology and Infectious Diseases Study Group for Antimicrobial Resistance Surveillance and Clinical Laboratory Standards Institute) on antibiotic surveillance, for which no recommendation for an informed consent has been issued. The diagnostic procedure (blood cultures) is part of the standard diagnostic work-up of patients suspected of having bacteraemia. Clinical information as presented, and information about use of antibiotics, was the standard information on the laboratory request form. Data were reviewed and analysed anonymously.

\section{Results}

A total of 320 blood samples from 320 different patients were cultured. The mean age of the patients was 21.6 years (range 0 - 75), and 162 were males and 158 females. Bacterial pathogens were detected in 170 cultures, $29.4 \%$ of which were from children ( $<17$ years). The distribution and percentages of the various bacterial isolates are shown in Table 1.

Isolates of Gram-negative bacteria (GNB) $(104,61.2 \%)$ were significantly more prevalent than Gram-positive isolates $(66,38.8 \%)$ $(p<0.05)$. Among the Gram-positive isolates, the predominant isolate was CoNS $(n=62)$; of these, 58 were susceptible to oxacillin. Four CoNS isolates displayed low susceptibility to oxacillin and were accordingly considered methicillin-resistant CoNS. Staphylococcus aureus was represented by three isolates, none resistant to oxacillin. Only one $S$. pneumoniae was isolated, from a blood sample of a 3-year-old girl; this isolate was resistant to erythromycin and amikacin, while retaining susceptibility to gentamicin. The Gram-negative isolates were overwhelmingly represented by Enterobacteriaceae (100/104 isolates). Enterobacteriaceae included E. coli (48.6\%), Klebsiella spp. (18.9\%) and Enterobacter spp. $(6.3 \%)$. Rare Enterobacteriaceae included Shigella spp., Salmonella spp, Citrobacter spp. and

Table 1. Distribution of isolates in blood cultures at BGH, February 2013 - January 2014

\begin{tabular}{llll}
\hline Bacterial isolate & Isolates, $\boldsymbol{n}$ & $\begin{array}{l}\text { \% of total isolates } \\
(\mathbf{N = 1 7 0})\end{array}$ & $\begin{array}{l}\text { \% of BSI pathogens } \\
(\mathbf{N = 1 1 2})\end{array}$ \\
\hline Escherichia coli & 54 & 31.8 & 48.2 \\
Klebsiella spp. & 21 & 12.4 & 18.3 \\
Enterobacter spp. & 7 & 4.1 & 6.3 \\
Shigella spp. & 6 & 3.5 & 5.4 \\
Salmonella spp. & 5 & 2.9 & 4.5 \\
Citrobacter spp. & 3 & 1.8 & 2.7 \\
Pseudomonas aeruginosa & 3 & 1.8 & 2.7 \\
Proteus spp. & 3 & 1.8 & 2.7 \\
Acinetobacter spp. & 1 & 0.6 & 0.9 \\
Neisseria spp. & 1 & 0.6 & 0.9 \\
Staphylococcus aureus & 3 & 1.8 & 2.7 \\
Methicillin-resistant CoNS & 4 & 2.4 & 3.6 \\
Streptococcus pneumoniae & 1 & 0.6 & 0.9 \\
Methicillin-susceptible CoNS & 58 & 34.1 & - \\
(contaminants) & & & \\
Total & 170 & 100 &
\end{tabular}


Table 2. Antimicrobial resistance (\%) in 104 Gram-negative blood isolates collected at BGH, February 2013 - January 2014

\begin{tabular}{|c|c|c|c|c|c|c|c|c|c|c|}
\hline $\begin{array}{l}\text { Antimicrobial } \\
\text { drug }\end{array}$ & $\begin{array}{l}\text { Escherichia } \\
\text { coli }(n=54)\end{array}$ & $\begin{array}{l}\text { Klebsiella } \\
\text { spp. } \\
(n=21)\end{array}$ & $\begin{array}{l}\text { Enterobacter } \\
\text { spp. }(n=7)\end{array}$ & $\begin{array}{l}\text { Citrobacter } \\
\text { spp. }(n=3)\end{array}$ & $\begin{array}{l}\text { Salmonella } \\
\text { spp. }(n=5)\end{array}$ & $\begin{array}{l}\text { Shigella } \\
\text { spp. } \\
(n=6)\end{array}$ & $\begin{array}{l}\text { Proteus } \\
\text { spp. } \\
(n=3)\end{array}$ & $\begin{array}{l}\text { Acinetobacter } \\
\text { spp. }(n=1)\end{array}$ & $\begin{array}{l}\text { Pseudomonas } \\
\text { aeruginosa } \\
(n=3)\end{array}$ & $\begin{array}{l}\text { Neisseria } \\
\text { spp. } \\
(n=1)\end{array}$ \\
\hline Amikacin & 5.6 & 4.8 & 0 & 0 & 0 & 0 & 66.7 & 0 & 0 & 0 \\
\hline Ampicillin & 98.1 & 95.2 & 100.0 & 100.0 & 100.0 & 83.3 & 66.7 & 100 & 100 & NT \\
\hline $\begin{array}{l}\text { Amoxicillin/ } \\
\text { clavulanate }\end{array}$ & 7.4 & 19.0 & 14.2 & 33.3 & 0 & 50.0 & 0 & 100 & 100 & NT \\
\hline Cefepime & 13.0 & 91 & 57.1 & 33.3 & 0 & 83.3 & 66.7 & NT & NT & NT \\
\hline Ceftazidine & 46.3 & 52.4 & 14.2 & 66.7 & 20 & 83.3 & 66.7 & 100 & 100 & NT \\
\hline Ceftriaxone & 24.1 & 19.0 & 28.5 & 33.3 & 80 & 83.3 & 0 & 100 & NT & NT \\
\hline Cefuroxine & 81.5 & 85.7 & 85.6 & 66.7 & 80 & 100 & 100 & 100 & 66.7 & NT \\
\hline Ciprofloxacin & 31.5 & 33.3 & 57.1 & 0 & 20 & 33.3 & 66.7 & 0 & 66.7 & 100 \\
\hline Erythromycin & 100 & 100 & 100 & 100 & 100 & 100 & 100 & 100 & 100 & NT \\
\hline Gentamicin & 7.4 & 28.6 & 14.2 & 0 & 100 & 100 & 66.7 & 0 & 0 & NT \\
\hline Imipenem & 0 & 4.8 & 0 & 0 & 0 & 0 & 0 & 0 & 0 & NT \\
\hline Co-trimoxazole & 100 & 100 & 100 & 100 & 100 & 100 & 100 & 100 & 100 & 100 \\
\hline $\begin{array}{l}\text { MDR } \\
\text { phenotype }\end{array}$ & 20.4 & 47.6 & 57.1 & 66.7 & 0 & 66.7 & 0 & 100 & 100 & 0 \\
\hline $\begin{array}{l}\text { ESBL- } \\
\text { producing } \\
\text { phenotype }\end{array}$ & 16.7 & 47.6 & 28.5 & 33.3 & 0 & 0 & 0 & NT & NT & NT \\
\hline $\mathrm{NT}=$ not tested. & & & & & & & & & & \\
\hline
\end{tabular}

Proteus spp. The four non-Enterobacteriaceae Gram-negative isolates included three Pseudomonas aeruginosa, one Acinetobacter spp. and one Neisseria spp.

Tables 2 and 3 show the antimicrobial susceptibility patterns of Gram-negative and Gram-positive bacterial isolates. With the exception of the two Proteus spp., Gramnegative isolates were often susceptible to amikacin, gentamicin and ciprofloxacin. The MDR phenotype was present in $36(34.6 \%)$ Gram-negative isolates, with $>50 \%$ also displaying an ESBL-production phenotype. Indeed, $82 \%$ MDR E. coli isolates were also ESBL producers, whereas $100 \%$ of Klebsiella spp. isolates displayed the ESBL-production phenotype. Of note, all Gram-negative bacilli displayed low susceptibility to co-trimoxazole, ampicillin and erythromycin. Worryingly, two MDR and ESBL-producing Klebsiella spp. isolates also displayed resistance to imipenem, one of the few carbapenems available in the province.

Nitrofurantoin, an oral drug displaying satisfactory activity against uropathogens in South Kivu, ${ }^{[18]}$ was not included in the antimicrobial panel because only parenteral antimicrobials were administered for the treatment of BSIs.

\section{Discussion}

BSI is associated with high mortality and high healthcare costs, especially when the bacteria

Table 3. Antimicrobial resistance (\%) in 8 Gram-positive blood isolates collected at BGH, February 2013 to January 2014

\begin{tabular}{llll}
\hline Antimicrobial drug tested & $\begin{array}{l}\text { Staphylococcus } \\
\text { aureus (3 isolates) }\end{array}$ & $\begin{array}{l}\text { CoNS } \\
(\mathbf{4} \text { isolates) }\end{array}$ & $\begin{array}{l}\text { Streptococcus pneumoniae } \\
\text { (1 isolate) }\end{array}$ \\
\hline Amikacin & 0 & 0 & 100.0 \\
Ampicillin & 100 & 75.0 & $\mathrm{NT}$ \\
$\begin{array}{l}\text { Sulphamethoxazole + } \\
\text { trimethoprim }\end{array}$ & 100 & 100 & $\mathrm{NT}$ \\
Clindamycin & 0 & & \\
Gentamicin & 0.00 & 0 & $\mathrm{NT}$ \\
Erythromycin & 33.3 & 50.0 & 0 \\
Oxacillin & 0 & 0 & 0 \\
Vancomycin & 0 & 10.0 & $\mathrm{NT}$ \\
NT = not tested. & & 0 & $\mathrm{NT}$
\end{tabular}

have low susceptibility to antimicrobial drugs. ${ }^{[22]}$ Accordingly, the implementation of laboratory capacity for specific diagnosis of causative bacterial agents and determination of their antimicrobial susceptibility profile is pivotal in curbing mortality related to BSI. Although blood cultures have been performed at our hospital for many years, they were characterised by a very low yield of positive isolates, with unreliable identification resulting in largely empirical treatment of presumptive BSI. Changes in the blood culture process in the past year have resulted in a spectacular rise in positive blood cultures in patients with suspected BSI. Despite these encouraging improvements, blood culture at our hospital is still plagued by a high rate of contaminant CoNS, when compared with benchmarks in the field. ${ }^{[23,24]}$ Action must therefore be taken to improve skin decontamination prior to blood sampling; the low susceptibility of CoNS to oxacillin needs further confirmation, as it has been shown that disc testing is not an accurate method for the determination of methicillin susceptibility of CoNS. ${ }^{[25]}$

In our study, $32.5 \%$ of blood cultures yielded significant positive growth. This rate 
is high when compared with rates in other African countries. ${ }^{[22,26-28]}$ We found a high prevalence of MDR GNB as major causative agents of BSI.

Among GNB, Enterobacteriaceae, particularly E. coli, were the most frequently isolated pathogens. Our results diverge from those previously reported in this province more than a decade ago that documented Salmonella spp. as the leading cause of bacteraemia in a rural paediatric hospital..$^{[5]}$ Oddly, Gram-positive bacteria did not play an important role in BSI when compared with other studies in developing countries; ${ }^{[15,27,29,30]}$ in fact, only three $S$. aureus and one S. pneumoniae were isolated. Given this steadily growing danger of MDR and ESBL-producing isolates in South Kivu, as underlined by our findings, a strict antibiotic policy should be implemented urgently in the province with an emphasis on local susceptibility findings. Another important issue in the province is the lack of regulation regarding prescription of antibiotics, which are widely used, even for minor illnesses such as rhinitis. Whereas no study has assessed this phenomenon, it is worth noting that a recent study documented a high level of irrational prescription of antibiotics by healthcare professionals in the Orientale Province of DRC, ${ }^{[31]}$ and that this practice is often associated with a steady increase of antimicrobial drug resistance in low-income countries. The identification of two carbapenem-resistant Klebsiella spp. isolates in the province is consistent with a recent observation of a carbapenem-resistant Enterobacter spp. in a urinary tract infection in the same province. ${ }^{[18]}$ The emergence and possible spread of carbapenem-resistant Enterobacteriaceae isolates in the province would represent an additional step in the wrong direction that might be enhanced by misuse of carpabenems, as observed a few years ago in some Asian countries. ${ }^{[32]}$

\section{Study limitations}

Our study has several limitations. We analysed only 320 blood cultures, a low number that might result in selection bias. Rates obtained during this study should therefore be interpreted with caution. Whereas no patient reported having HIV infection, no objective data were available regarding HIV status of BSI patients.

\section{Conclusion}

Although performed on a limited set of blood cultures, our study underscores the high prevalence of MDR-resistant bacteria responsible for BSI at BGH. The high rate of MDR ESBL-producing GNB is consistent with a previous study performed on isolates from urinary tract infections at the same hospital. Accordingly, these findings should compel provincial healthcare stakeholders to take immediate action aimed at tackling this dangerous trend, before the situation slips beyond any possible repair. These actions should include the establishment of guidelines for prescription of antimicrobial drugs and the setting up of antimicrobial drug control in the province.

Author contributions. LMI, LK and RBC participated in the design of the study, LMI oversaw the data collection, LMI and LK were responsible for the laboratory assays, and FBK, MI and PNM contributed to implementation of blood culture assays. LMI wrote the first draft of the article, and all the authors participated in the manuscript revision. All the authors read and approved the final manuscript.

Acknowledgments. We thank the staff of the Clinical Biology Department at BGH for their technical assistance. We also gratefully acknowledge the assistance of Olga Mineeva (Université catholique de Louvain) and AnneSophie Piette (Institut Royal Supérieur de la Défense-Koninlijk Hoger Instituut voor Defensie). This project was funded by Belgian Cooperation
Agency through the 2012 PIC project (Projet Inter-Universitaire de Coopération) of the ARES (Académie de Recherche et d'Enseignement Supérieur) and by the Department Management of Scientific \& Technological Research of Defence (IRSD-RSTD; Royal High Institute for Defence) supporting research and development (grants MED-20).

\section{References}

1. Shah H, Bosch W, Thompson KM, Hellinger WC. Intravascular catheter-related bloodstream infection. The Neurohospitalist 2013;3(3):144-1451. [http://dx.doi.org/10.1177/1941874413476043]

2. Laupland KB. Incidence of bloodstream infection: A review of population-based studies. Clin Microbiol Infect 2013;19(6):492-500. [http://dx.doi.org/10.1111/1469-0691.12144]

3. Coburn B, Morris AM, Tomlinson G, et al. Does this adult patient with suspected bacteremia require blood cultures? JAMA 2012;308(5):502-511. [http://dx.doi.org/10.1001/jama.2012.8262]

4. Bates DW, Pruess KE, Lee TH. How bad are bacteremia and sepsis? Outcomes in a cohort with suspected bacteremia. Arch Intern Med 1995;155(6):593-598. [http://dx.doi.org/10.1001/ archinte.1995.00430060050006, http://dx.doi.org/10.1001/archinte.155.6.593]

5. Bahwere P, Levy J, Hennart P, et al. Community-acquired bacteremia among hospitalized children in rural central Africa. Int J Infect Dis 2001;5(4):180-188. [http://dx.doi.org/10.1016/S1201in rural central

6. Hounsom L, Grayson K, Melzer M. Mortality and associated risk factors in consecutive patients 6. Hounsom L, Grayson K, Melzer M. Mortality and associated risk factors in consecutive patients
admitted to a UK NHS trust with community acquired bacteraemia. Postgrad Med J 2011;87(1033):757762. [http://dx.doi.org/10.1136/pgmj.2010.116616]

762. [http://dx.doi.org/ $10.1136 / \mathrm{pgmj} .2010 .116616]$
7. Lillie PJ, Allen J, Hall C, et al. Long-term mortality following bloodstream infection. Clin Microbiol Infect 2013;19(10):955-960. [http://dx.doi.org/10.1111/1469-0691.12101]

8. Moszynski P. 5.4 million people have died in Democratic Republic of Congo since 1998 because of conflict, report says. BMJ 2008;336(7638):235. [http://dx.doi.org/10.1136/bmj.39475.524282.DB]

9. Coghlan B, Brennan RJ, Ngoy P, et al. Mortality in the Democratic Republic of Congo: A nationwide survey. Lancet 2006;367(9504):44-51. [http://dx.doi.org/10.1016/S0140-6736(06)67923-3]

10. Kandala NB, Mandungu TP, Mbela K, et al. Child mortality in the Democratic Republic of Congo: Cross-sectional evidence of the effect of geographic location and prolonged conflict from a national household survey. BMC Public Health 2014;14:266. [http://dx.doi.org/10.1186/1471-2458-14-266]

11. Kandala NB, Emina JB, Nzita PD, et al. Diarrhoea, acute respiratory infection, and fever among children in the Democratic Republic of Congo. Soc Sci Med 2009;68(8):1728-1736. [http://dx.doi. children in the Democratic Republic
org/10.1016/j.socscimed.2009.02.004]

12. Black RE, Cousens S, Johnson HL, et al. Global, regional, and national causes of child mortality in 2008: A systematic analysis. Lancet 2010;375(9730):1969-1987. [http://dx.doi.org/10.1016/S0140-
676 2008: A systematic

13. Evans JA, Adusei A, Timmann C, et al. High mortality of infant bacteraemia clinically indistinguishable from severe malaria. QJM 2004;97(9):591-597. [http://dx.doi.org/10.1093/qjmed/hch093]

14. Factor SH, Schillinger JA, Kalter HD, et al. Diagnosis and management of febrile children using the WHO/UNICEF guidelines for IMCI in Dhaka, Bangladesh. Bull World Health Organ 2001;79(12):1096-1105.

15. Van Herp M, Parqué V, Rackley E, et al. Mortality, violence and lack of access to healthcare in the Democratic Republic of Congo. Disasters 2003(2);27:141-153. [http://dx.doi.org/10.1111/14677717.00225]

16. Magiorakos AP, Srinivasan A, Carey RB, et al. Multidrug-resistant, extensively drug-resistant and pandrug-resistant bacteria: An international expert proposal for interim standard definitions for acquired resistance. Clin Microbiol Infect 2012;18(3):268-281. [http://dx.doi.org/10.1111/j.14690691.2011.03570.x]

17. Kang CI, Kim SH, Park WB, et al. Bloodstream infections caused by antibiotic-resistant Gram-negative bacilli: Risk factors for mortality and impact of inappropriate initial antimicrobial therapy on outcome. Antimicrob Agents Chemother 2005;49(2):760-766. [http://dx.doi.org/10.1128/AAC.49.2.760-766.2005]
A

Antimicrob Agents Chemother 2005;49(2):760-766. [http://dx.doi.org/10.1128/AAC.49.2.760-766.2005]
18. Irenge LM, Kabego L, Vandenberg O, et al. Antimicrobial resistance in urinary isolates from inpatients . Irenge LM, Kabego L, Vandenberg O, et al. Antimicrobial resistance in urinary isolates from inpatients
and outpatients at a tertiary care hospital in South-Kivu Province (Democratic Republic of Congo). BMC Res Notes 2014;7:374. [http://dx.doi.org/10.1186/1756-0500-7-374]

19. Baron EJ. Processing and interpretation of blood cultures. In: Isenberg HD, ed. Essential Procedures for Clinical Microbiology. Washington, DC: ASM Press, 1998:58-62.

20. EUCAST Clinical breakpoints. 2015. http://www.eucast.org/fileadmin/src/media/PDFs/EUCAST_ files/Breakpoint_tables/v_5.0_Breakpoint_Table_01.pdf (accessed 21 December 2014).

21. Drieux L, Brossier F, Sougakoff W, et al. Phenotypic detection of extended-spectrum beta-lactamase production in Enterobacteriaceae: Review and bench guide. Clin Microbiol Infect 2008;14(Suppl 1):90-103. [http://dx.doi.org/10.1111/j.1469-0691.2007.01846.x].

22. Blomberg B, Jureen R, Manji KP, et al. High rate of fatal cases of pediatric septicemia caused by Gram-negative bacteria with extended-spectrum beta-lactamases in Dar es Salaam, Tanzania. J Clin Gram-negative bacteria with extended-spectrum beta-lactamases in Dar es Salaam,
Microbiol 2005;43(2):745-749. [http://dx.doi.org/10.1128/JCM.43.2.745-749.2005]

23. Schifman RB, Strand CL, Meier FA, et al. Blood culture contamination: A College of American Pathologists Q-Probes study involving 640 institutions and 497134 specimens from adult patients.
Pantion Pathologists Q-Probes study involving 640
Arch Pathol Lab Med 1998;122(3):216-221.

24. Murillo TA, Beavers-May TK, English D, et al. Reducing contamination of peripheral blood cultures in a pediatric emergency department. Pediatr Emerg Care 2011;27(10):918-921. [http://dx.doi. org/10.1097/PEC.0b013e318230285b]

25. York MK, Gibbs L, Chehab F, et al. Comparison of PCR detection of mecA with standard susceptibility testing methods to determine methicillin resistance in coagulase-negative staphylococci. J Clin Microbiol 1996;34(2):249-253.

26. Berkley JA, Lowe BS, Mwangi I, et al. Bacteremia among children admitted to a rural hospital in Kenya. N Engl J Med 2005;352(1):39-47. [http://dx.doi.org/10.1056/NEJMoa040275]

27. Reddy EA, Shaw AV, Crump JA. Community-acquired bloodstream infections in Africa: A systematic review and meta-analysis. Lancet Infect Dis 2010;10(6):417-432. [http://dx.doi.org/10.1016/S14733099(10)70072-4]

28. Lochan H, Bamford C, Eley B. Blood cultures in sick children. S Afr Med J 2013;103(12):918-920. [http://dx.doi.org/10.7196/SAMJ.6979]

29. Murdoch DR. Microbiological patterns in sepsis: What happened in the last 20 years? Int J Antimicrob Murdoch DR. Microbiological patterns in sepsis: What happened in the last 20 years?
Agents 2009;34(Suppl 4):S5-S8. [http://dx.doi.org/10.1016/S0924-8579(09)70557-6]

30. Moyo S, Aboud S, Kasubi M, et al. Bacteria isolated from bloodstream infections at a tertiary hospital in Dar es Salaam, Tanzania - antimicrobial resistance of isolates. S Afr Med J 2010(12);100:835-838.

31. Thriemer K, Katuala Y, Batoko B, et al. Antibiotic prescribing in DR Congo: A knowledge, attitude and practice survey among medical doctors and students. PloS One 2013;8(2):e55495. [http://dx.doi. org/10.1371/journal.pone.0055495]

32. Poirel L, Revathi G, Bernabeu S, et al. Detection of NDM-1-producing Klebsiella pneumoniae in Kenya. Antimicrob Agents Chemother 2011;55(2):934-936. [http://dx.doi.org/10.1128/AAC.01247-10].

Accepted 20 July 2015 